stances are secondary products generated through a series of enzymatic reactions in some aromatic plants. These substances may function to prevent or repel invasions of pathogens or pests, or to lure or attract pollination insects. The substances are usually secreted by glands, and exist in at least one of the organs, such as roots, stems, leaves, flowers, fruits and seeds. In plants, most of them are usually in free states, but some are combined with sugar, forming glycosides.

Aromatic plants usually contain four ingredients, aromatic, medicinal, nutrient and pigment. In addition, they sometimes also contain antioxidants and antibacterial ingredients, which not only increase their value, but also widen the area of use. They can be used as aromatic plants, medicinal herbs, food, ornamentals, or even as natural anti-bacterial or anti-corrosion agents or anti-oxidants.

In ancient times, Egyptians, Chinese, Mesopotamians, Greeks and Romans had begun to use aromatic plants for sterilization, anti-corrosion, medical care, health care, beauty and preservation of body, and so on. From the 13th century, distillation began to be the method used to extract oil from aromatic plants. Until the 16th century, Europeans successfully extracted essential oils, such as turpentine, rosemary oil, and lavender oil from the aromatic plants. Since the 19th century, with the development of science and technology, the exploration and use of the aromatic plants have rapidly expanded. So far, the world has discovered nearly 100 families, 200 genera, and more than 3600 species of aromatic plants, most of which are distributed in the tropical and subtropical regions. By the early 1980s, China had discovered more than 350 species of aromatic plants, among which about 150 species have been commonly used in the production of spices. The geographical distribution areas of the aromatic plants in China are over virtually all of the country. Some provinces and autonomous regions have become important bases for cultivation of aromatic plants.

Obviously, effective exploitation, utilization and protection of the aromatic plant resources need to recog- nize the background information, summarize the present knowledge and carry out further researches in detail and in depth. The timely publication of the book Aromatic Plants in China meets such demand in at least some of these aspects. The book is a systematic and comprehensive monograph of the aromatic plant resources and their present status in China. The book was written based on countrywide data from an investigation on the aromatic plant resources, and the large amount of literature on the aromatic plants in China and abroad. The book is divided into two major parts, general introduction and special issues. The 632 color pictures are particularly helpful for readers to recognize and identify the aromatic plant species. In the first part, the basic knowledge of the aromatic plants, is introduced in categories of aromatic plants, their distributions, productions, main ingredients, functions, extraction, processing and uses, etc. In the second, the characteristics of each family, genus and species of the thousands of aromatic plants is given in detail, with Latin name, alias, English name, origin, distribution, biological characteristics, main points of cultivation techniques, main ingredients of essential oils, and the present situation of usage. At the end of the book, the strategies for the further exploitation, use and protection of the wild aromatic plant resources in China were put forward.

The book is suitable for the persons who engage in biology, agronomy, forestry, horticulture, plant chemistry, and other related scientific fields. Those who carry out investigation, cultivation, identification, research, processing, marketing, or use of the aromatic plants, will find it particularly useful. It will be valued by any persons who are interested in the aromatic plants.

\section{Li DeZHI ${ }^{1}$ and QIN AILI ${ }^{2}$}

${ }^{1}$ Labratory of Urbanization and Ecological Restoration of Shanghai; National Field Observation and Research Station in Tiantong Forest Ecosystem of Zhejiang; Department of Environmental Science, East China Normal University, 3663, Zhongshan Road (N), Shanghai, China 200062

${ }^{2}$ Jilin Forestry Staff School, Jilin, China 130000

[Book Review Editor's note. Aweto is a Maori name for Dong Chong Tsia Tsiao (winter caterpillar summer grass). This is the caterpillar of a moth Hepialus armoricanus (Lepidoptera: Hepialidae) infected with an obligate fungus Cordyceps sinensis (Clavicipitales, Ascomycotina). The caterpillar lives underground in alpine grasslands in Tibet and the Himalayas for five years where it is attacked while feeding on roots. The fungus invades, killing and mummifying the larvae near the tops of their burrows. The $5-15 \mathrm{~cm}$ fruiting body emerges from the ground in spring from the forehead of the caterpillar, like "summer grass." The medicinal agent is likely Cordycepin, or 3-deoxyadenosine. Most aweto sold as pills in the west are probably fake or nearly so.]

\title{
Aweto in China
}

By Northwest Plateau Institute of Biology, CAS and Institute of Drug Quarantine of Qinghai Province, 2008, Shaanxi Science and Technology Publishing House, 744 pages, Price: $120 \mathrm{CNY}$.

Aweto is the complex of the stroma of Cordyceps sinensis parasitizing the larva of Hepialus armoricanus living through the winter. As a special organism, aweto is characterized by a worm in winter and a grass in sum- mer, which is also the origin of its Chinese name. At present in the world, there are more than 400 species of fungi in the genus of Cordyceps parasitizing the larvae of insects, spiders and other organisms forming the carposporophyte, among which there are 68 species in China. In China, aweto resource is distributed in Sichuan, Yunnan, Guizhou, Gansu, Qinghai, Tibet and other areas. 
Some scholars in China and abroad regarded all the fungi of Cordyceps parasitizing other types of organisms forming the carposporophyte as the aweto. However, the traditional Chinese medicinal theory, and most Chinese scholars, only regarded the aweto as Cordyceps sienesis parasitizing the larva of the organisms in Insecta, Lepidoptera, Hepialidae and Hepialus distributed in the alpine meadow areas of Qinghai-Tibet Plateau of China, form the complex of larva and fungi.

Aweto is one of the three most precious medicinal herbs and tonics. It is well known world wide due to its strange morphology, abundant nutrient, and magical medicinal effects. It is believed to benefit without the harm of ginseng. The ingredients of aweto are adenosine, mannitol, aweto acid, polysaccharides, and other bioactive chemicals. It is reported that the main pharmacological effects of aweto are regulation of human immunity functions, hormone-like effects, restraining cough, protection of kidney, strengthening the hematopoiesis, anti-aging, diminishing the rejection effects of organ transplants, inhibition of lupus, decrease of blood sugar, and anti-tumour properties. Among more than 800 Chinese medicinal herbs, aweto is the only type with dual effects of complement for both Yin and Yang according to the traditional Chinese medicinal theory. In ancient times, aweto was an exclusive tribute to the aristocracy in the royal palace in China.

In recent years, because of the high prices in the market, more and more people have plucked aweto in China, the so-called soft gold, unregulated, just like the "gold rush" in the western United States in the middle period of the $19^{\text {th }}$ century. However, due to its scarcity in nature and the rapid increase in demand, the habitat of aweto were seriously damaged or even desertified. Aweto as a resource is decreasing rapidly and becoming more and more endangered. Nowadays, aweto has

\section{Chinese Wild Orchids}

By Chen Xinqi, Ji Zhanhe and Luo Yibo. 2008. Science Press, Beijing. 416 pages, Price: $260 \mathrm{CNY}$.

Orchidaceae is one of the largest and most diverse families in Angiospermae. Orchids have been regarded by some scholars as reaching the culmination of the evolution of plants. So far, Orchidaceae contains more than 700 to 800 genera and 25000 to 30000 species, and more than 100000 hybrid species and varieties. In China, there are about 174 genera and more than 1300 species in Orchidaceae. Orchids are mainly distributed in Asia and America, especially Central and South America. According to the living habits and growth forms, orchids generally can be divided into three categories: the terrestrial orchids, epiphytic orchids, and saprophytic orchids (very rare in many other plants). In his classic work, Darwin (1862) used the theory of evolution to explain the adaptation and evolution of orchid plants based on a mass of facts and been listed as a national key protected wild plant of level-II in China. The protection and research on the natural aweto resources are becoming imperative.

The book Aweto in China is the first comprehensive and systematic monograph on the various aspects of aweto resources in China, including the properties, biological basis, ecological characteristics, life history pattern, biological engineering, characteristics in herbal science and pharmacognosy, pharmacological effects, chemical ingredients, its role in health care, its other various applications, its research history and the present states of aweto resources.

The book contains 9 chapters, 41 sections, and more than 220 figures. The main contents are as follows: Chapter 1 fungus and aweto, Chapter 2 basic biological research on aweto, Chapter 3 ecological research on aweto, Chapter 4 research on the biological engineering of aweto, Chapter 5 chemical research on aweto, Chapter 6 herbal science and pharmacognosy of aweto, Chapter 7 pharmacological research on aweto, Chapter 8 roles of aweto in medicine and health care, and Chapter 9 research on the roles of aweto in biological control.

The book was well written with few errors, and can be easily understood by non-scientists. Abundant illustrations are helpful for readers to easily understand the explanations. The book is suitable for readers who engage in biology, taxonomy, agriculture, medicinal plants and other related fields, or other persons who are interested in aweto.

\section{DEZHI ${ }^{1}$ and QIN AILI ${ }^{2}$}

${ }^{1}$ Labratory of Urbanization and Ecological Restoration of Shanghai; National Field Observation and Research Station in Tiantong Forest Ecosystem of Zhejiang; Department of Environmental Science, East China Normal University, 3663, Zhongshan Road (N), Shanghai, China 200062

${ }^{2}$ Jilin Forestry Staff School, Jilin, China 130000

detailed tests and observations. Although there were some mistakes in his explanations, most of the conclusions are still reliable nowadays. After Darwin, orchids have attracted more and more researchers all over the world.

Chinese orchids usually have beautiful slender leaves and faintly-scented flowers. The quiet elegance of orchids has been deeply advocated and praised by the Chinese people for thousands of years. The character of orchids was compared to a man of honour by Confucius in his book, Dialogue at Home. Orchids not only have been popularly used as ornamental plants, but some also have been used as medicinal plants, spices and so on. The cultivation of orchid plants has a long history in China and the world.

The wild orchid plants are not used intensively at present, but they are of potential value in the future, and they are also important as a natural gene pool. 


\section{Erratum The Canadian Field-Naturalist 126(4)}

In response to the review of Contributions to the History of Herpetology. CFN 126(3): 344-345, the book's editor Kraig Adler pointed out (personal communication to FRC 12 May 2013): "Only one small correction. Mrs. Martof used a kitchen knife, not a gun. She told the police she slipped while cutting some pizza. But Bernie was stabbed up under his rib cage several times!"

\section{Erratum The Canadian Field-Naturalist}

It has come to our attention that sections of many of the book reviews by Li Dezhi and Qin Aili were copied from sources without attribution. The journal and the authors apologize for this oversight. 